\title{
Abdominal wall endometrioma mimicking an incarcerated hernia: a case report
}

This article was published in the following Dove Press journal:

International Journal of General Medicine

28 June 2012

Number of times this article has been viewed

\author{
Christos Simoglou' \\ Paul Zarogoulidis ${ }^{2}$ \\ Nikolaos Machairiotis ${ }^{3}$ \\ Konstantinos Porpodis ${ }^{2}$ \\ Lambros Simoglou ${ }^{4}$ \\ Alexandros Mitrakas ${ }^{5}$ \\ Agisilaos Esebidis ${ }^{5}$ \\ Eirini Sarika ${ }^{6}$ \\ George Kouklakis ${ }^{7}$ \\ Alkis lordanidis ${ }^{8}$ \\ Nikolaos Katsikogiannis ${ }^{3}$ \\ 'Cardiothoracic Surgery Department, \\ University General Hospital of \\ Alexandroupolis, Democritus University of \\ Thrace, Greece; ${ }^{2}$ Pulmonary Department, \\ "G Papanikolaou” General Hospital, \\ Aristotle University of Thessaloniki, \\ Greece; ${ }^{3}$ Surgery Department (NHS), \\ University General Hospital of \\ Alexandroupolis, Greece; ${ }^{4}$ Surgical Clinic \\ (NHS), Komotini General Hospital, \\ Thrace, Greece; ${ }^{5}$ Ist University Surgery \\ Department, University General Hospital \\ of Alexandroupolis, Democritus University \\ of Thrace, Greece; ' ${ }^{6}$ Biopathology \\ Department, University General Hospital \\ of Alexandroupolis, Democritus University \\ of Thrace, Greece; ${ }^{7}$ Gastrointestinal \\ Endoscopy Unit, University General \\ Hospital of Alexandroupolis, Democritus \\ University of Thrace, ${ }^{8}$ Radiology \\ Department, University General Hospital \\ of Alexandroupolis, Democritus University \\ of Thrace, Greece
}

Correspondence: Paul Zarogoulidis Pulmonary Department,

"G Papanikolaou” General Hospital,

Aristotle University of Thessaloniki,

Greece

Tel +00 30697727 I 974

Fax +00 302310992433

Email pzarog@hotmail.com

\begin{abstract}
The case of a tender, isolated abdominal wall tumor within a Pfannenstiel incision due to a seeding deposit of endometrial tissue secondary to a previous obstetric operation (caesarean section) in a 39-year-old female without previously reported pelvic endometriosis is presented. The lesion clinically mimicked the appearance of an incarcerated incisional hernia at the outer corner of the healed Pfannenstiel incision. The preoperative differential diagnosis also included that of a locally forming post-operative tender granuloma and the remote possibility of an incisional endometrioma (although no link to menstruation could be made). Local malignancy was not taken as a serious possibility. Definitive diagnosis of the excised lesion was made at histology. The pre-operative diagnostic dilemma is presented, along with a short review of the literature.
\end{abstract}

Keywords: endometrioma, seeding endometriosis, abdominal wall tumor

\section{Introduction}

Endometriosis is defined as the presence of normal endometrial mucosa abnormally implanted in locations other than the uterine cavity. The ectopic implants are located in the minor pelvis, the ovaries, the fallopian tubes, and the uterosacral ligaments. More unusual implantation sites are the abdominal scars, scars of the perineum, the navel, the spleen, the kidney, the gallbladder, the pleura, and the nasal mucosa. This condition is not present before menarche, because the ectopic tissue possesses the same steroid and estrogen receptors as normal endometrium and is capable of responding to the normal cyclic hormonal milieu. ${ }^{1,2}$

Endometriosis is the more common cause of chronic pelvic pain in females. Its prevalence has been estimated to $1 \%-2 \%$ of reproductive age females and is more common $(15 \%-25 \%)$ among women with infertility problems. ${ }^{1}$

\section{Case presentation}

A 39-year-old female patient was referred to our Hospital's Emergency Surgical Department with a palpable tender mass at the left corner of a Pfannenstiel incision. Medical history revealed that this mass presented four months ago $(2 \mathrm{~cm}$ diameter at the left end of her abdominal incision), and since then it exhibited interrupted abdominal tenderness, but with no identifiable pattern of exacerbation. During the last 4 months she received analgesics for intermittent pain management. She had a typical Pfannenstiel skin incision having healed normally after having a child birth 4 years and 8 months before admission. Thus the patient was immediately admitted 
for further evaluation and treatment. The mass was immobile and clinically, aside from the possibility of an incarcerated incisional hernia, one could also entertain the diagnosis of a locally forming tender granuloma or that of a seeding deposit of ectopic endometrial tissue. There was no evidence to support the possibility of a soft tissue neoplastic growth. No other pathologic findings were recorded. The patient's laboratory results (general blood count and serum biochemistry) were all within the normal range with no indication of an inflammatory response of significance. Plain chest and abdominal X-rays failed to provide conclusive evidence of any pathology. Thus the patient was programmed without further delay for an exploratory operation scheduled for the next available operation room.

The abdominal skin was re-incised along the outer third of the previous incision and the subcutaneous layer was dissected free of the underlying abdominal musculature. Upon reaching the lower lateral border of the left rectus abdominus muscle, a hard mass was palpated. This mass infiltrated the external oblique, the internal oblique, and the transverse abdominus musculature and reached down to the preperitoneal fat layer. The mass was excised en-block with a small portion of surrounding abdominal wall musculature (Figure 1). A small suction drain was placed preperitoneally and the abdominal wall defect was closed in one layer using a non-absorbable monofilament suture followed by the placement of a synthetic non-absorbable mesh. The excised specimen was sent for histological examination.

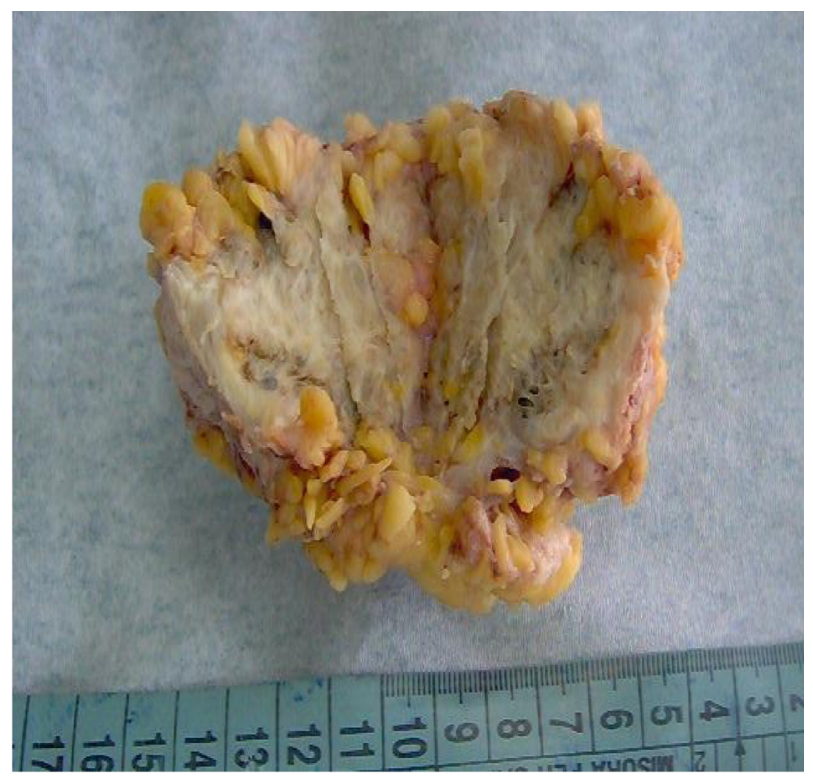

Figure I Gross appearance of the surgical specimen.

Note: Areas of recent blood infiltrates within the mass are evident upon immediate on-table scalpel division of the tumor.
The histology report concerned a specimen $3.5 \times 2.2 \mathrm{~cm}$ in dimension containing fibrous, adipose, and skeletal muscular tissue. Within this tissue specimen, multiple sites of endometriosis were revealed. No findings of malignancy were reported.

\section{Discussion}

The finding of ectopic endometrial tissue within the abdominal wall seems to occur among $0.03 \%$ to $1 \%$ of women who have undergone prior gynecologic or obstetric surgery, and has been noticed particularly after cesarean section. ${ }^{3-6}$ Its prevalence as an isolated abdominal wall mass is reported in $4 \%$ of the endometrioma cases in another series. ${ }^{7}$ Other studies report an incidence of $1.04 \%$ in patients previously operated on the uterus and $0.046 \%$ in those who underwent previous cesarean section. ${ }^{8}$ Other authors have reported a much higher incidence of about $0.2 \%$ of the cesarean sections performed. ${ }^{9}$

The literature seems to agree that the clinical appearance of a triad consisting of periodic abdominal scar pain (associated with menses), a history of cesarean section, and an underlying tumor inside a surgical scar is more often than not confirmed to be an endometrioma. ${ }^{10}$ Moreover, the presentation is atypical and thus the preoperative diagnosis poses difficulties in differential diagnosis. ${ }^{11,12}$ What most authors agree about is the fact that definitive diagnosis can only be established by pathologic analysis of the specimen.

In our case, the patient did not link the unsteady nature of the periodic exacerbation of the pain followed by total pain remittance, with her menstruation. The clinical examination revealed a $2 \mathrm{~cm}$ hard, immobile, tender mass, which was definitely located within the abdominal wall musculature. Thus, an all too familiar irreducible incisional hernia with bouts of incarceration was viewed as the most likely diagnosis. The absence of specific intestinal symptoms allowed us to formulate an alternative diagnosis of the possible existence of a post-operative incisional granuloma formation, attributed to the possible presence of underlying suture material or the formation of an incisional endometrial tumor. Malignancy was unlikely, but a small soft tissue sarcoma could not be readily ruled out. During operative dissection no hernia was found and the operative diagnosis tilted towards the existence of a hard granulomatous lesion forming from the scar or fibrous tissue of the previous operation. The patient's post-operative course was uneventful and she was discharged on the third post-operative day in excellent condition. The histology report unveiled the true nature of the malady. The patient was followed up 5 months post-operatively and 
was found well. No symptoms or clinical indications of relapse were evident.

This case comes to add to the well-known need to elicit an as accurate as possible history from the patient in which all pieces of information are pertinent, no matter how insignificant they may initially seem. The literature reports a limited number of cases similar to this one. It seems that it is a relatively rare finding, given the number of performed cesarean sections. Although endometriosis was suspected in most cases, in nearly all, the diagnosis was made histologically. Reliable pre-operative diagnosis has been reported with the use of ultrasonography in experienced hands, with the MRI Scan (T1/T2), which can detect blood within the endometrioma, and with the performance of a simple needle aspirate followed by cytological evaluation. The significance of having a reliable clinical diagnosis of an endometrioma lies in the fact that some patients may benefit from hormonal and anti-inflammatory therapy, thus reducing the need for operative intervention in a given number of patients.

\section{Acknowledgments}

All authors contributed equally to the writing and presentation of the case.

\section{Disclosure}

The authors report no conflicts of interest in this work.

\section{References}

1. Streuli I, de Ziegler D, Borghese B, Santulli P, Batteux F, Chapron C. New treatment strategies and emerging drugs in endometriosis. Expert Opin Emerg Drugs. March 23, 2012. [Epub ahead of print.]

2. Römer T. Treatment of endometriosis. Med Monatsschr Pharm. 2012; 35(2):44-51; quiz 53-54.

3. Merran S, Karila-Cohen P. Incisional subcutaneous endometrioma of the abdominal wall: report of two cases. $J$ Radiol. 2004;85(4 Pt 1): 409-410.

4. Vélez SE, Piccinni DJ, Caminos S, Spitale LS, Ferrari JC. Abdominal wall endometriosis: case report. Rev Fac Cien Med Univ Nac Cordoba. 2004;61(1):44-47.

5. Ozel L, Sagiroglu J, Unal A, et al. Abdominal wall endometriosis in the cesarean section surgical scar: a potential diagnostic pitfall. $J$ Obstet Gynaecol Res. Mar 2012;38(3):526-530. Epub February 16, 2012.

6. Donati M, Gandolfo L, Cavallaro G, Ciancio F, Brancato G. Endometriosis of the abdominal wall (authors' experience). Ann Ital Chir. 2004;75(1):29-34; discussion 34.

7. Blanco RG, Parithivel VS, Shah AK, Gumbs MA, Schein M, Gerst PH. Abdominal wall endometriomas. Am J Surg. 2003;185(6):596-598.

8. Zhao XY, Lang JH, Leng JH, et al.Clinical characteristics of abdominal wall endometrioma and its recurrence-related factors. Zhonghua Fu Chan Ke Za Zhi. 2004;39(2):97-100.

9. Khammash MR, Omari AK, Gasaimeh GR, Bani-Hani KE. Abdominal wall endometriosis. An overlooked diagnosis. Saudi Med J. 2003;24(5):523-525.

10. Esquivel-Estrada V, Briones-Garduño JC, Mondragón-Ballesteros R. Endometriosis implant in cesarean section surgical scar. Cir Cir. 2004; 72(2):113-115.

11. Capasso L, Sciano D, Iarrobino G, et al. Extrauterine endometriosis: three new cases. G Chir. 2004;25(1-2):39-42.

12. Divani S, Vardouli A, Exarhos N, Lioupis A. Endometriosis in the differential diagnosis of abdominal wall masses. Acta Cytol. 2003;47(5):944-945.
International Journal of General Medicine

\section{Publish your work in this journal}

The International Journal of General Medicine is an international, peer-reviewed open-access journal that focuses on general and internal medicine, pathogenesis, epidemiology, diagnosis, monitoring and treatment protocols. The journal is characterized by the rapid reporting of reviews, original research and clinical studies across all disease areas.

\section{Dovepress}

A key focus is the elucidation of disease processes and management protocols resulting in improved outcomes for the patient. The manuscript management system is completely online and includes a very quick and fair peer-review system. Visit http://www.dovepress.com/ testimonials.php to read real quotes from published authors. 